\title{
A facility for conducting high-temperature oxidation experiments of alloys in helium environments containing part per million levels of impurities
}

\author{
Deepak Kumar, Christopher J Torbet and Gary S Was \\ Department of Materials Science and Engineering, University of Michigan, Ann Arbor, MI, USA \\ E-mail: kumardee@umich.edu
}

Received 21 May 2009, in final form 7 July 2009

Published 30 July 2009

Online at stacks.iop.org/MST/20/095708

\begin{abstract}
An experimental facility was constructed to study the corrosion of alloys in helium containing part per million (ppm) levels of $\mathrm{CO}, \mathrm{CO}_{2}, \mathrm{CH}_{4}$ and $\mathrm{H}_{2}$ as impurities, relevant to the environment in the heat exchanger of the Very High Temperature Gas Cooled Reactor. The system provides the capability of exposing multiple specimens in up to seven separate helium environments, simultaneously, for durations of $>1000 \mathrm{~h}$ and temperatures up to $1200^{\circ} \mathrm{C}$. Impurity concentrations are controlled down to $1 \mathrm{ppm}$ accuracy and analyzed using a discharge ionization detector gas chromatograph. The utility and reliability of the facility in quantitatively accounting for the masses of reactants and products involved in the oxidation of alloy 617 at $900{ }^{\circ} \mathrm{C}$ and $1000{ }^{\circ} \mathrm{C}$ in the helium gas containing $15 \mathrm{ppm} \mathrm{CO}$ and $1.5 \mathrm{ppm} \mathrm{CO}_{2}$ is confirmed by the weight-gain measurements, gas-phase analysis and post-test microstructural analysis.
\end{abstract}

Keywords: VHTR, helium coolant, corrosion, experimental facility

(Some figures in this article are in colour only in the electronic version)

\section{Introduction}

Helium gas is used as a coolant in the Very High Temperature Gas Cooled Reactor (VHTR) and contains ppm levels of CO, $\mathrm{CO}_{2}, \mathrm{CH}_{4}, \mathrm{H}_{2}$ and $\mathrm{H}_{2} \mathrm{O}$ as the main impurities. In this design, the He gas with outlet temperature up to $1000{ }^{\circ} \mathrm{C}$ will pass through an intermediate heat exchanger where it will transfer heat to a secondary coolant. The viability of the VHTR concept requires an understanding of the gas-metal reactions that will take place between metal surfaces and impurities at these high temperatures. The impurities react with the metallic surfaces of the heat exchanger resulting in oxidation, oxide reduction, carburization or decarburization depending on the impurity concentration, temperature and alloy composition. Oxidation consumes the metal and reduces the load-bearing cross section of the component. Carburization leads to lowtemperature embrittlement [1] and decarburization reduces the creep strength [2]. Thus, the assessment of the mechanisms and rates of degradation are critical to the viability of this concept.

Due to the emergence of the VHTR as a high-priority advanced reactor concept, there is a growing level of interest and activity in evaluating the corrosion and creep strength of heat-exchanger materials in impure helium. Yet only two other facilities exist with the capability of conducting oxidation experiments in impure helium: the CORRALINE facility at CEA, France [3, 4], and the impure helium loop at Idaho National Laboratory (INL), USA [5]. Both facilities are unique and control the impurity levels down to $\sim 1 \mathrm{ppm}$. The CORRALINE facility consists of a horizontal quartz tube 


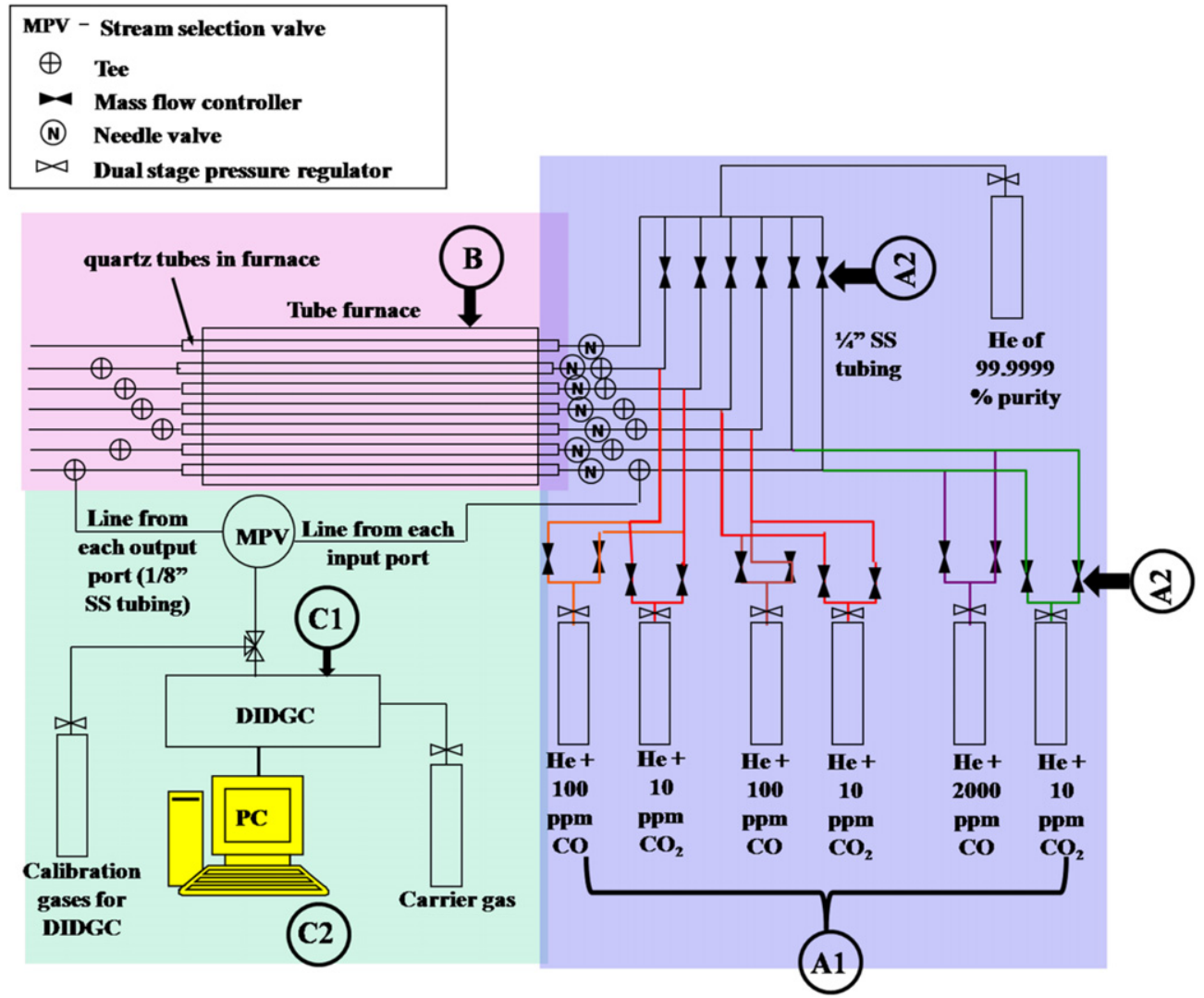

Figure 1. Schematic diagram of the controlled-impurity helium flow system. The three major sections, gas mixing section (A1 and A2), exposure section (B), and the gas-analysis section (C1 and $\mathrm{C} 2$ ), are shaded in different colors.

reactor inserted in a high-temperature furnace and is capable of exposing four corrosion coupons with total surface area $\sim 6 \mathrm{~cm}^{2}$ in two environments simultaneously [4]. The INL facility, on the other hand, consists of concentric quartz tubes housed in a vertical furnace and is capable of exposing multiple samples simultaneously in one environment. Further, in this set up provisions are made to achieve gas flow rate as high as $401 \mathrm{~min}^{-1}$ to study the effect of flow rate [5]. Both facilities have been validated by simple experiments and are currently operational. However, the limitation of these facilities is that at a given time only one or two environments can be evaluated simultaneously. The goal of the facility at the University of Michigan was to construct a system with high throughput in which multiple specimens can be evaluated in multiple gas environments simultaneously. The second goal was to control the experimental variables such as impurity concentrations (in ppm levels), flow rate and temperature for long exposure duration, and to quantitatively evaluate the concentrations of impurities in the range of $1 \mathrm{ppm}$ level in both the inlet and outlet gas streams.

The objective of this paper is to describe and demonstrate the capabilities of the controlled-impurity helium flow system built at the University of Michigan. The paper is divided into the following major sections: section 2 focuses on a description of the capabilities of the facility, section 3 documents on the reliability and repeatability of the system and section 4 describes the dependability of the overall facility determined via a $100 \mathrm{~h}$ oxidation experiment of alloy 617 in the helium gas containing $15 \mathrm{ppm}$ of $\mathrm{CO}$ and $1.5 \mathrm{ppm}$ of $\mathrm{CO}_{2}$.

\section{Description of the facility}

The facility consists of three major sections: a gas mixing section, an exposure section and a gas analysis section. Figure 1 is a schematic of the facility in which the gas mixing section is labeled as ' $A$ ', the exposure section as ' $B$ ' and the analysis section as ' $C$ '. Figure 2 shows photographs of these major sections of the system. The purpose of the gas mixing section is to obtain the desired concentration of each impurity inside the quartz tube using premixed, bottled gases and a series of mass flow controllers. Helium with controlled levels of impurities is then passed through the exposure section in which the corrosion coupons in the quartz tubes are exposed to the flowing gas mixture. A tee and a needle valve at the furnace entrance control the flow rate of the gas mixture through this section. The impurity levels in the helium gas are analyzed continuously both before and after the entry into the furnace using the discharge ionization detector gas chromatograph (DIDGC) in the analysis section. The experimental variables such as the flow rates of gases and concentration levels of impurities are continuously monitored using a personal computer (PC). 
A2

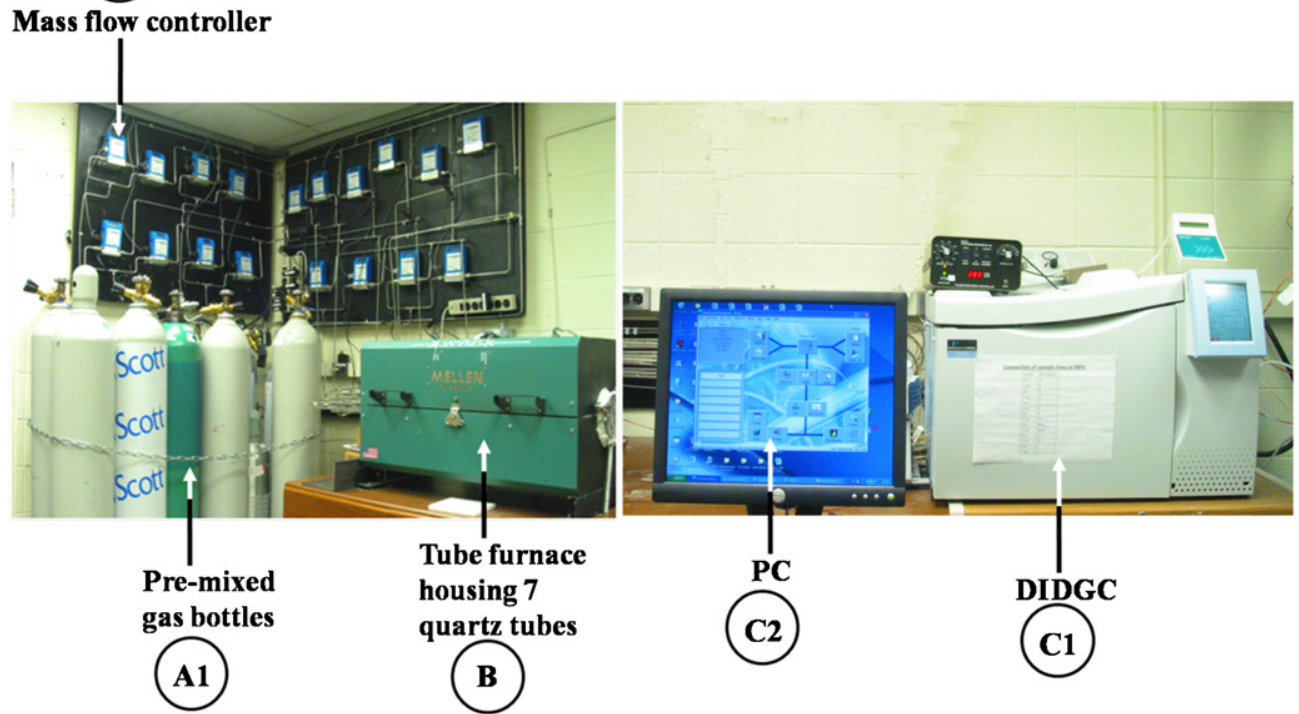

Figure 2. Photograph of the assembled controlled-impurity helium flow system.

\subsection{Gas mixing section}

The gas mixing section consists of 7 premixed gas bottles (A1 in figures 1 and 2) and 18 mass-flow controllers (A2 in figures 1 and 2). To obtain the gas mixture with the target concentration of each impurity, a certified level of one type of impurity, e.g. $100 \mathrm{ppm}$ of $\mathrm{CO}$, from a pre-mixed gas cylinder of helium and a controlled amount of another impurity from a different certified pre-mixed bottle are combined using electronic massflow controllers from Omega, Inc. If required, the resulting impurity gas mixture is diluted by mixing it with ultra-high purity helium of $99.9999 \%$ purity. The electronic mass-flow controller used for gas mixing has an accuracy of $\pm 1 \mathrm{ml} \mathrm{min}^{-1}$ with a full scale operation range of $0-100 \mathrm{ml} \mathrm{min}^{-1}$, and is capable of withstanding pressures up to $500 \mathrm{psig}$. All of the components involved in transporting and mixing the gases were made up of 316 stainless steel. Whenever possible, weld fittings were used for connecting lines from different gas bottles to avoid the in-leakage of air.

\subsection{Exposure section}

The exposure section consists of a horizontal, $75 \mathrm{~cm}$ long, three-zone tube furnace housing seven $1.25 \mathrm{~cm}$ outer diameter quartz tubes. Six out of the seven tubes are arranged along the periphery of the process diameter in the furnace, whereas the seventh tube is inserted in the middle. The six tubes arranged along the periphery are attached to the premixed He gas, thus enabling corrosion studies in six separate environments simultaneously. The seventh tube is attached to an ultra-high purity helium cylinder for reference. If required, this seventh tube may also be used to expose samples in laboratory air. The horizontal tube furnace is rated for temperatures up to $1200{ }^{\circ} \mathrm{C}$ and is a split tube design, which can be opened for easy access to the tubes. The three temperature zones of this furnace are controlled by independent controllers with $1{ }^{\circ} \mathrm{C}$ resolution.
One R-type thermocouple is inserted into the middle of each zone for temperature monitoring. The temperature of the three zones can be tuned to obtain a uniform temperature zone of length $15 \mathrm{~cm}$, in which the temperature variation, as well as that between tubes, is $\pm 2{ }^{\circ} \mathrm{C}$. This long uniform temperature zone enables the exposure of multiple samples in each tube, which can be moved from the hot zone to the cold zone at different exposure durations. The length of the cold zone is $\sim 20 \mathrm{~cm}$ with a temperature less than $100{ }^{\circ} \mathrm{C}$ at a helium gas flow rate of $100 \mathrm{ml} \mathrm{min}^{-1}$.

A custom-designed push rod is used to remove the samples while maintaining an airtight seal to the tubes. The push rod consists of a quartz rod with five hooks and an encapsulated steel rod at the end and resides completely inside the quartz tube. A magnet is used to manipulate the push rod. Figures 3(a), (b) and $(c)$ show a photograph of the push rod and the magnet used to manipulate it. The manipulating magnet is marked as ' $A$ ', the encapsulated steel rod is marked as ' $\mathrm{B}$ ' and the five hooks are marked with the letters ' $\mathrm{C}$ ' to ' $G$ ', respectively. The five-hook design of the push rod was adopted to overcome the limitation of the small space available for the manipulation of the push rod. The uniform hot zone, where the corrosion coupons are exposed, lies between 30 and $45 \mathrm{~cm}$ from the exit of the furnace. This requires at least $45 \mathrm{~cm}$ of the manipulation space beyond the furnace end so that the corrosion coupons can be pulled out from the farthest position in the uniform hot zone. However, the length of the cold zone (the distance beyond the furnace end) is only $20 \mathrm{~cm}$, which is shorter than the required length of $45 \mathrm{~cm}$ by $25 \mathrm{~cm}$. The five-hook design in which the hooks are out of phase from each other by $90^{\circ}$ helps to overcome this limitation. When the sample is at the farthest position from the furnace end, the first hook (marked as ' $G$ ' in figure 3) is engaged in moving the sample for $\sim 20 \mathrm{~cm}$ after which the second hook (' $\mathrm{D}$ ' in figure 3 ) is engaged in moving the sample for the next $20 \mathrm{~cm}$. Before the second hook can be engaged, the push rod is rotated 
(a)

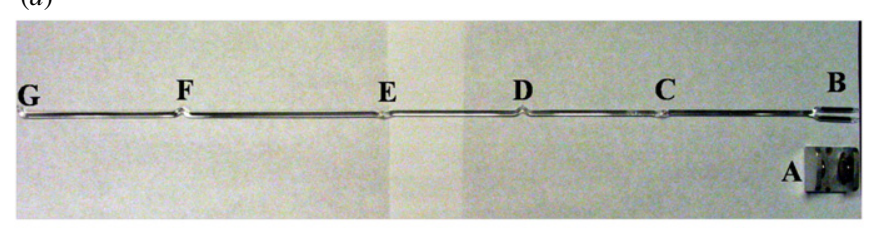

(b)

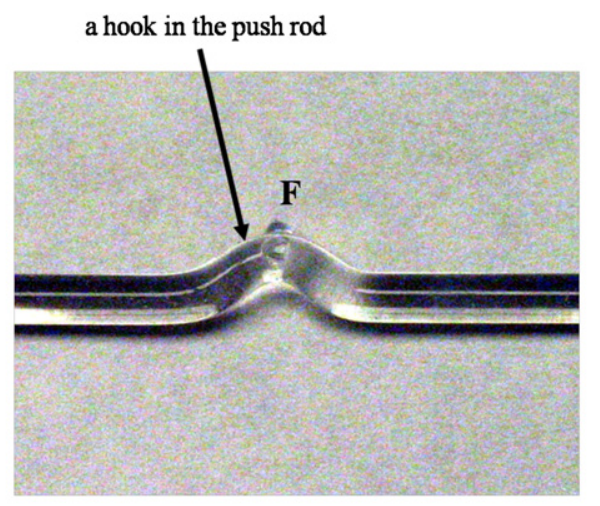

(c)

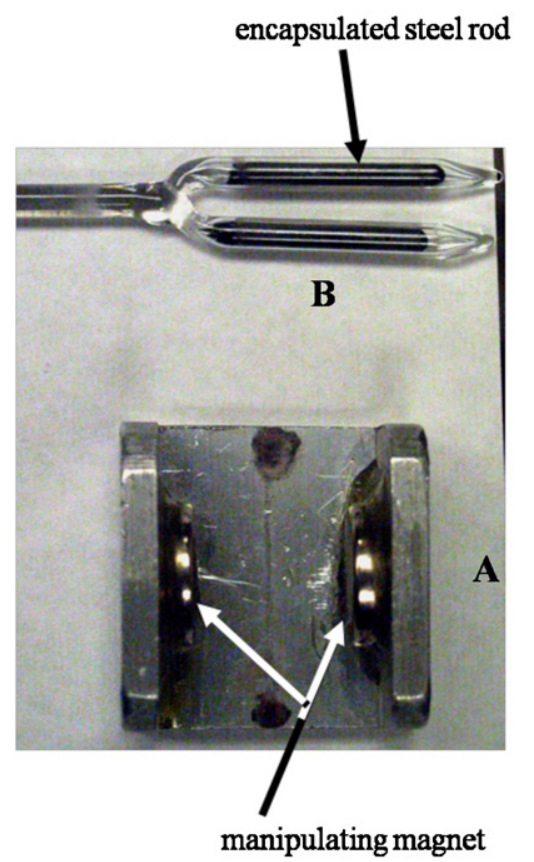

Figure 3. (a) Custom-fabricated quartz push rod to move the specimen from the hot zone to cold zone of the furnace without breaking the seal. A is the high-strength magnet, $\mathrm{B}$ is the encapsulated steel, C, D, E, F and G are five hooks used to move the samples, $(b)$ high magnification of the push rod showing the shape of the hook, the manipulating magnet and encapsulated steel rod $(c)$.

by $90^{\circ}$ to disengage the first hook and engage the second hook. If required, the third, fourth and fifth hooks are employed in a similar manner to pull the coupons completely out in the cold zone without having to break the seal of the system.

\subsection{Gas analysis section}

The third section is the gas-analysis section, consisting of the DIDGC and the PC (figures 1 and 2). The DIDGC is used to continuously analyze the gas mixture both before and after the exposure section, and the PC is used to control the GC and to record the data.
The important components in the DIDGC are the columns (K1, K2 and $\mathrm{K} 3$ in figure 4) and the detector (DID in figure 4). The columns, which are kept in a temperaturecontrolled oven, separate the individual components in the gas mixture by first adsorbing them and then later releasing them during a controlled temperature ramp. The gas components thus released are then transported to the detector by an inert carrier gas where, by virtue of their characteristic ionization energies, they are identified and quantified.

Figure 4 shows the details of the DIDGC used in the facility. It consists of two sample loops where a total of $0.25 \mathrm{ml}$ of an unknown gas mixture is retained for the analysis, three capillary columns $\mathrm{K} 1, \mathrm{~K} 2, \mathrm{~K} 3$ that reside in an oven with temperature control of $\pm 0.1{ }^{\circ} \mathrm{C}$ and separate out the individual components in the gas mixture, and a pulsed discharge ionization detector (DID) which identifies and quantifies the components of the unknown gas mixture. Two pneumatically actuated valves (eight-port and six-port valves in figure 4) are provided for facilitating the appropriate routing of gases during analysis. Helium gas with total impurity $<10 \mathrm{ppb}$ is used as the carrier gas. The impurity level is obtained by additional purification of research grade helium of $99.9999 \%$ purity through an impurity trapper (HP2, from Valco, Inc.), which traps $\mathrm{H}_{2} \mathrm{O}, \mathrm{H}_{2}, \mathrm{O}_{2}, \mathrm{~N}_{2}, \mathrm{NH}_{3}, \mathrm{CO}, \mathrm{CO}_{2}$ and $\mathrm{CH}_{4}$ from helium.

The flow path of the carrier gas during the analysis of an unknown gas mixture through the DIDGC is shown by different colors in figure 4 . The arrows on the diagram show the flow direction of the gases during analysis. First the carrier gas from the bottle is divided (' $\mathrm{T}$ ' in figure 4) into two streams (colored in blue and green). The blue stream flows through sample loop 1, which transports the unknown gas mixture to columns $\mathrm{K} 1$ and $\mathrm{K} 2$ via port numbers $1^{\prime}$ and $2^{\prime}$. Column K2 is a molecular sieve column where the actual separation of $\mathrm{H}_{2}, \mathrm{Ar}, \mathrm{O}_{2}, \mathrm{~N}_{2}$ and $\mathrm{CH}_{4}$ occurs, whereas column $\mathrm{K} 1$ acts as a trap which stops the unwanted hydrocarbons from going to column K2. Column K2 cannot separate out $\mathrm{CO}_{2}$ from the gas mixture. Another column, $\mathrm{K} 3$, is used to separate $\mathrm{CO}_{2}$ from the gas mixture. The green flow path shows the routing of the carrier gas in column K3 and the arrows show its flow direction.

Figure 5 shows a representative chromatogram obtained from the DIDGC for a gas mixture containing $2 \mathrm{ppm}$ of $\mathrm{CO}_{2}, \mathrm{H}_{2}, \mathrm{O}_{2}, \mathrm{~N}_{2}, \mathrm{CH}_{4}$ and $\mathrm{H}_{2}$ in helium. The elution of the components from the columns was done by holding the oven at $50^{\circ} \mathrm{C}$ for the first $5 \mathrm{~min}$, followed by ramping to $120{ }^{\circ} \mathrm{C}$ at $7{ }^{\circ} \mathrm{C} \mathrm{min}{ }^{-1}$ until all gases elute completely from columns $\mathrm{K} 2$ and $\mathrm{K} 3$. Peaks 1 and 2 in this chromatogram correspond to the unresolved gas mixture peak of the helium matrix and other unresolved trace gases, such as Ne and heavy hydrocarbons. As shown in figure 5(a), the first peak of interest in this chromatogram is $\mathrm{CO}_{2}$ followed by $\mathrm{H}_{2}, \mathrm{O}_{2}, \mathrm{~N}_{2}, \mathrm{CH}_{4}$ and $\mathrm{CO}$. The $\mathrm{CO}_{2}$ and $\mathrm{H}_{2}$ gases are eluted at the oven temperature of $50{ }^{\circ} \mathrm{C}$, whereas other gases come out during ramping of the oven temperatures. The effect of temperature ramping results in a rise of the baseline of the detector's response; however, the quantification of the gases remains unchanged as the shape and area of the peaks above the background do not alter. 


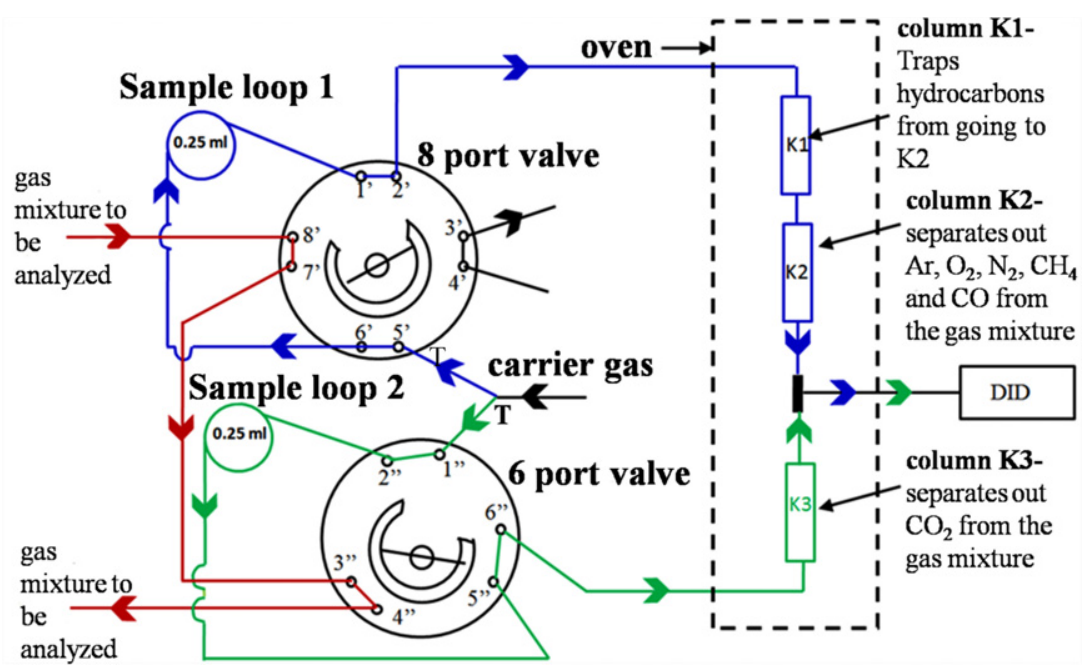

Figure 4. Flow path of the carrier gas inside the DIDGC during analysis of an unknown gas mixture. The carrier gas from the bottle splits in two streams at position ' $\mathrm{T}$ ' and flows in the sample loops 1 (colored in blue) and 2 (colored in light green). The separation of $\mathrm{Ar}, \mathrm{O}_{2}, \mathrm{~N}_{2}$ and $\mathrm{CH}_{4}$ occurs in column $\mathrm{K} 2$, whereas column $\mathrm{K} 3$ is used to separate $\mathrm{CO}_{2}$ from the unknown gas mixture.

For good repeatability of the DIDGC, it is important to completely resolve the individual components in the gas mixture. Figure 5 shows the separation of the $\mathrm{CO}_{2}, \mathrm{H}_{2}, \mathrm{Ar}$, $\mathrm{O}_{2}, \mathrm{CH}_{4}$ and $\mathrm{CO}$ from each other. The magnified portion of the chromatogram near the $\mathrm{CO}_{2}$ peak and $\mathrm{Ar} / \mathrm{O}_{2}$ peak is also shown in figures $5(b)$ and $(c)$. As is evident from the figure, peaks 1 and $\mathrm{CO}_{2}$ are well separated from each other, but the peaks for $\mathrm{O}_{2}$ and $\mathrm{Ar}$ lie very close to each other. Proper care is taken to separate these two peaks; particular attention is paid on maintaining the constant flow rate of the carrier gas through the columns and the precise controlling of the oven temperature which collectively control the elution of components from the columns and hence their separation.

\section{Characterization of the facility}

The controlled-impurity flow system is designed to control the impurity concentration in the gas stream to $\sim 1 \mathrm{ppm}$. At these low concentrations of impurities it is important to establish the repeatability and reliability of the system. The important capabilities that should be determined are as follows: repeatability of gas analysis through the DIDGC, the tightness to which the concentration levels of reacting species can be controlled in the reaction zone over a long experiment and the adsorption or desorption of gases in an empty quartz tube at high temperatures. Further, since high-temperature oxidation in a dilute environment is subjected to a rapid depletion of the reactive species in the environment [6], which might alter the oxidation mechanism/kinetics, an experiment was conducted to determine the minimum flow rate of the helium gas required to avoid significant depletion of the reactants during an exposure experiment.

\subsection{Repeatability of the gas analysis}

The repeatability of the gas analysis through the DIDGC was determined for $\mathrm{CO}, \mathrm{CO}_{2}, \mathrm{H}_{2}, \mathrm{O}_{2}$ and $\mathrm{CH}_{4}$ by analyzing the certified gas mixture, from Matheson-Trigas, Inc., in five
Table 1. Composition of the gases used to calibrate the DIDGC.

\begin{tabular}{lccccr}
\hline & $\begin{array}{l}\mathrm{CO}_{2} \\
(\mathrm{ppm})\end{array}$ & $\begin{array}{l}\mathrm{H}_{2} \\
(\mathrm{ppm})\end{array}$ & $\begin{array}{l}\mathrm{CH}_{4} \\
(\mathrm{ppm})\end{array}$ & $\begin{array}{l}\mathrm{O}_{2} \\
(\mathrm{ppm})\end{array}$ & $\begin{array}{l}\mathrm{CO} \\
(\mathrm{ppm})\end{array}$ \\
\hline Cylinder 1 & 2 & 50.5 & 10.1 & 2 & 10.1 \\
Cylinder 2 & 20.1 & 7492.8 & 199.8 & 15 & 3012.3 \\
\hline
\end{tabular}

Table 2. Repeatability of the gas analysis through the DIDGC in the low concentration range of impurities.

\begin{tabular}{lll}
\hline Gas & $\begin{array}{l}\text { Certified } \\
\text { concentrations } \\
(\mathrm{ppm})\end{array}$ & $\begin{array}{l}\text { Average and standard deviation } \\
\text { of five measurements by DIDGC } \\
\text { (ppm) }\end{array}$ \\
\hline $\mathrm{CO}$ & 10.1 & $9.9 \pm 0.3$ \\
$\mathrm{CO}_{2}$ & 2.0 & $2.2 \pm 0.1$ \\
$\mathrm{CH}_{4}$ & 10.1 & $10.1 \pm 0.1$ \\
$\mathrm{H}_{2}$ & 50.5 & $48.4 \pm 0.9$ \\
$\mathrm{O}_{2}$ & 2.0 & $2.7 \pm 0.8$ \\
\hline
\end{tabular}

Table 3. Repeatability of gas analysis through the DIDGC in the high concentration range of impurities.

\begin{tabular}{lcc}
\hline Gas & Expected concentration (ppm) & Average of five runs (ppm) \\
\hline $\mathrm{CO}$ & 3012.3 & $2998.4 \pm 4.6$ \\
$\mathrm{CO}_{2}$ & 20.1 & $20.7 \pm 0.3$ \\
$\mathrm{CH}_{4}$ & 199.8 & $193.1 \pm 1.8$ \\
$\mathrm{H}_{2}$ & 3003.2 & $3017.5 \pm 8.0$ \\
$\mathrm{O}_{2}$ & 15.0 & $16.7 \pm 1.26$ \\
\hline
\end{tabular}

separate runs. The temperature was maintained at $21{ }^{\circ} \mathrm{C}$ and the flow rate of the gas mixture during analysis was set at $50 \mathrm{ml} \mathrm{min}{ }^{-1}$. Table 1 shows the composition of the certified cylinders 1 and 2 used for the analysis. The composition of the cylinders was chosen such that the repeatability of the DIDGC could be determined at both low (cylinder 1) and high concentrations (cylinder 2) of gases.

Tables 2 and 3 present the results of the analysis of the gases given in column 1. In these tables, columns 2 


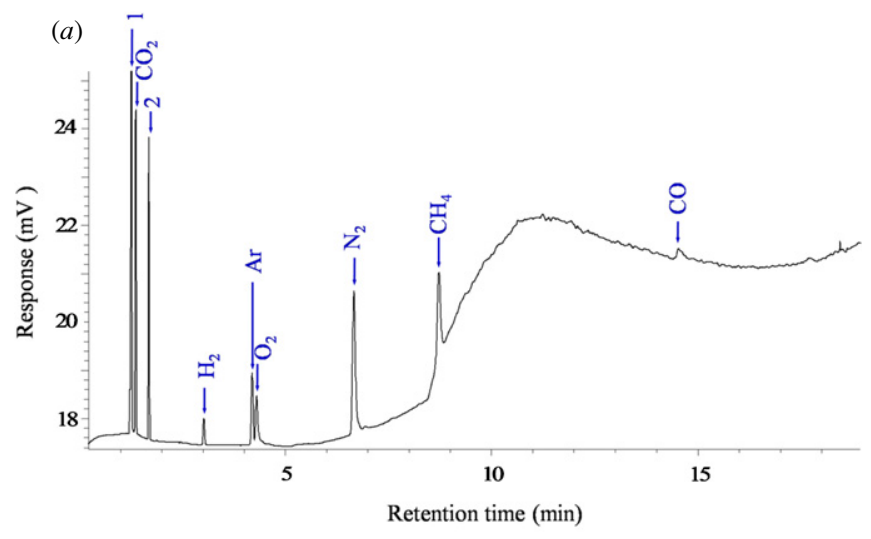

(b)

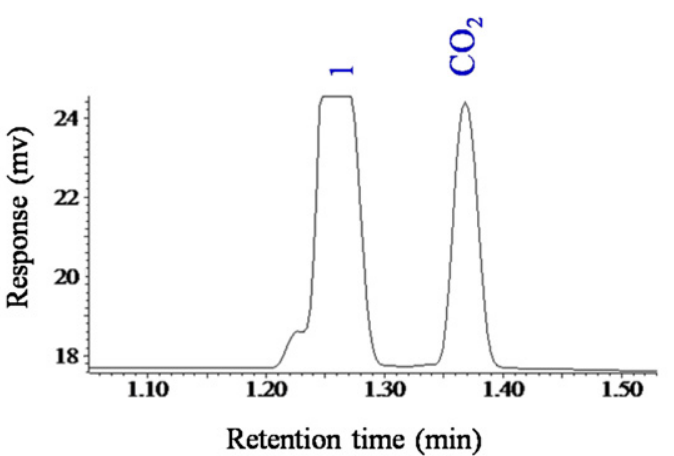

(c)

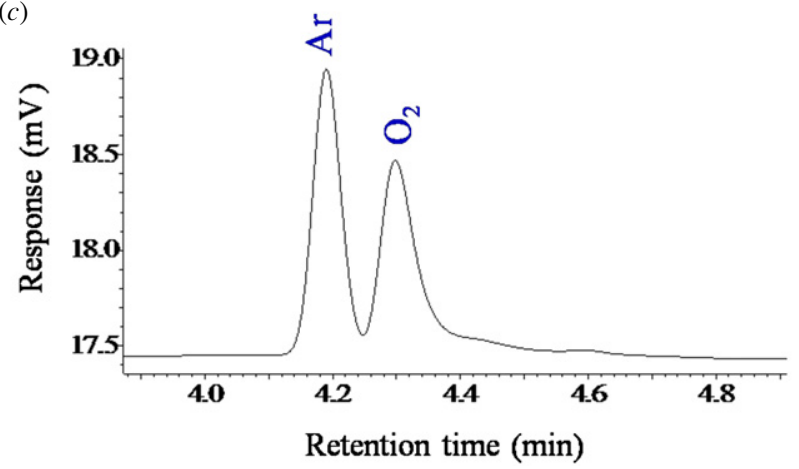

Figure 5. (a) A representative chromatogram obtained for a gas mixture containing $2 \mathrm{ppm}$ of $\mathrm{CO}_{2}, \mathrm{H}_{2}, \mathrm{O}_{2}, \mathrm{Ar}, \mathrm{N}_{2}, \mathrm{CH}_{4}$ and $\mathrm{CO}$ in helium. Peaks 1 and 2 are the unresolved gas mixture peaks, (b) portion of the chromatogram showing the peak separation between peak 1 and $\mathrm{CO}_{2}$ and $(c)$ portion of the chromatogram showing the peak separation between $\mathrm{Ar}$ and $\mathrm{O}_{2}$.

and 3 show the certified concentration of the gases, and the average and standard deviation of the five runs measured by the DIDGC, respectively. The difference between the average of the measured runs and the certified concentration represents the DIDGC's quantification reliability. The standard deviation of the runs (column 3 in tables 2 and 3) represents the repeatability of the gas analysis through the DIDGC. As is evident from the data in table 2, at the low concentration of impurities, the average concentration measured by the DIDGC is close to the certified concentration demonstrating the reliability of the DIDGC in quantifying the gases. Further, the standard deviations of the five runs for various gases are $<1 \mathrm{ppm}$, suggesting that from a practical standpoint, the readings from the DIDGC are reliable up to $1 \mathrm{ppm}$.

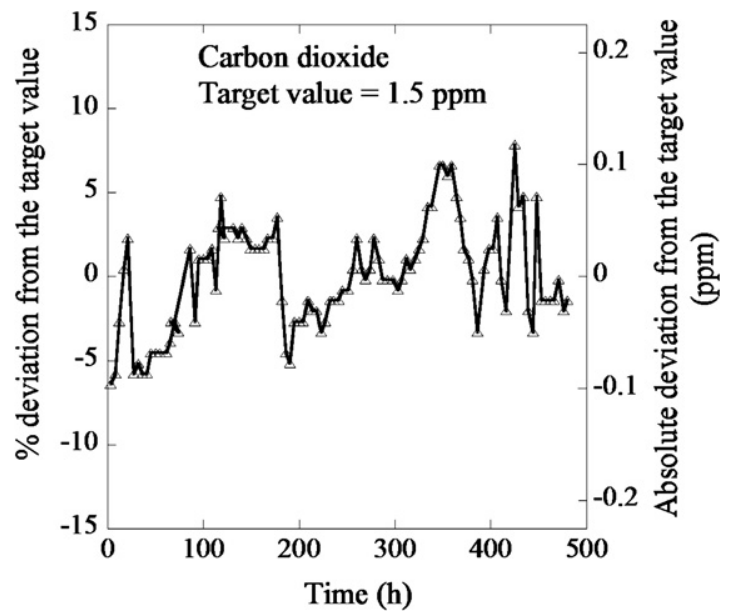

Figure 6. Plot of the percentage deviation of $\mathrm{CO}_{2}$ at the inlet of the quartz tube over $500 \mathrm{~h}$ of exposure duration. The absolute deviation of the inlet concentration is shown on the right-hand side $y$-axis. The maximum deviation of concentration from the target value of $1.5 \mathrm{ppm}$ was $8 \%$, which corresponds to an absolute deviation of $0.1 \mathrm{ppm}$.

Table 3 shows the repeatability of the DIDGC at the higher concentrations of impurities. As shown in this table, the average concentrations of the five measurements are very close to the certified concentration and also the standard deviation $<10$ ppm showing that at the high concentrations it is reliable up to $10 \mathrm{ppm}$.

\subsection{Control of gas chemistry in the reaction zone}

One of the goals of the facility is to control the inlet impurity concentrations tightly in a long exposure duration experiment so that the oxygen and carbon potentials in helium (set by the impurity concentrations) can be maintained throughout the experiment. Corrosion of alloys in impure helium is governed by the oxygen or carbon potentials in the environment (proportional to the $\mathrm{CO} / \mathrm{CO}_{2}$ ratio for a $\mathrm{He}+\mathrm{CO}+\mathrm{CO}_{2}$ environment). To evaluate this capability, the deviation of the $\mathrm{CO}$ and $\mathrm{CO}_{2}$ concentrations from the target value was recorded at the inlet of the reaction zone in a $500 \mathrm{~h}$ long experiment. Figures 6 and 7 present the deviation of the inlet concentrations of $\mathrm{CO}_{2}$ and $\mathrm{CO}$ from the target values as a function of exposure duration. The target values in this case were $1.5 \mathrm{ppm}$ of $\mathrm{CO}_{2}$ and $1908 \mathrm{ppm}$ of $\mathrm{CO}$, respectively. As shown in figure 6 , the maximum deviation of $\mathrm{CO}_{2}$ at the inlet was $0.1 \mathrm{ppm}$ at the target value of $1.5 \mathrm{ppm}$, which is below the resolution of the DIDGC. The maximum deviation of $\mathrm{CO}$ from the target value of $1908 \mathrm{ppm}$ was $3.5 \%$, which corresponds to an absolute deviation of $69 \mathrm{ppm}$ (figure 7). These results show that in long exposure duration experiments the impurity levels in the reaction zone can be tightly controlled with a maximum deviation of $\pm 3.5 \%$ from the target value. The maximum deviation of $3.5 \%$ of impurities in the reaction zone corresponds to $<10 \%$ deviation in the target oxygen or carbon potentials over the exposure duration of $500 \mathrm{~h}$, which from the experimental point of view is acceptable. 


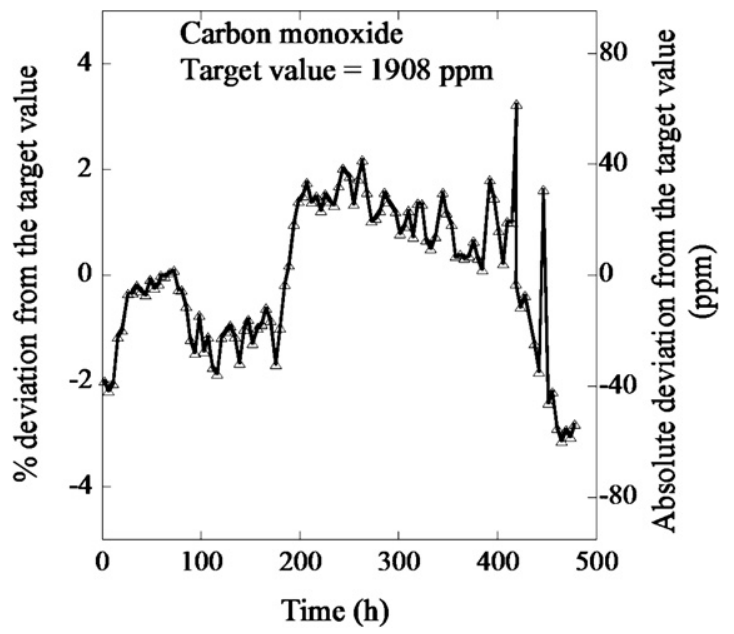

Figure 7. Plot of the percentage deviation of $\mathrm{CO}$ at the inlet of the quartz tube over $500 \mathrm{~h}$ of exposure duration. The absolute deviation of the inlet concentration is shown on the right-hand side $y$-axis. The maximum deviation of concentration from the target value of $1908 \mathrm{ppm}$ was $3.5 \%$, which corresponds to an absolute deviation of $69 \mathrm{ppm}$.

Table 4. Measured concentration of $\mathrm{CO}$ at the inlet and outlet of the tube at four temperatures.

\begin{tabular}{llll}
\hline $\begin{array}{l}\text { Temperature } \\
\left({ }^{\circ} \mathrm{C}\right)\end{array}$ & Inlet $(\mathrm{ppm})$ & Outlet $(\mathrm{ppm})$ & $\begin{array}{l}\text { \% change } \\
\text { from the inlet }\end{array}$ \\
\hline RT & $241 \pm 1.6$ & $243 \pm 1.6$ & 0.8 \\
900 & $241 \pm 2.1$ & $242 \pm 2.4$ & 0.4 \\
950 & $243 \pm 1.8$ & $237 \pm 1.9$ & 2.5 \\
1000 & $242 \pm 1.7$ & $234 \pm 2.9$ & 3.3 \\
\hline
\end{tabular}

\subsection{Characterization of the quartz tubes}

In order to verify that there was no significant adsorption or desorption of gases from the quartz tubes, helium gas containing $242 \mathrm{ppm} \mathrm{CO}$ and $1.5 \mathrm{ppm} \mathrm{CO}_{2}$ was flowed through an empty quartz tube, and the inlet and outlet concentration of $\mathrm{CO}$ at four temperatures, $20^{\circ} \mathrm{C}, 900{ }^{\circ} \mathrm{C}, 950{ }^{\circ} \mathrm{C}$ and $1000{ }^{\circ} \mathrm{C}$, were measured. Prior to the measurements at high temperature the tube was baked at $1050{ }^{\circ} \mathrm{C}$ under the nitrogen gas at a flow rate of $90 \mathrm{ml} \mathrm{min}{ }^{-1}$. Table 4 shows the average and standard deviation of the measured $\mathrm{CO}$ concentration at the inlet and outlet of the tube for each of the four temperatures. At each temperature seven separate measurements were made. As is evident from this table, the variation of the inlet and outlet concentrations at the four temperatures is $\sim 3 \%$ which is comparable to the repeatability of gas analysis through the DIDGC. Thus, baking of the tube at a temperature above that for the experiment ensures that the quartz tube neither adds nor removes gas from the stream.

\subsection{Determination of minimum flow rate to avoid starvation}

A rapid depletion of the reacting species adjacent to the metal surfaces can occur when a reactive metal surface is exposed to a flowing gas mixture containing dilute amount of reactive species (in ppm level) in inert gas [6]. In this case the reaction

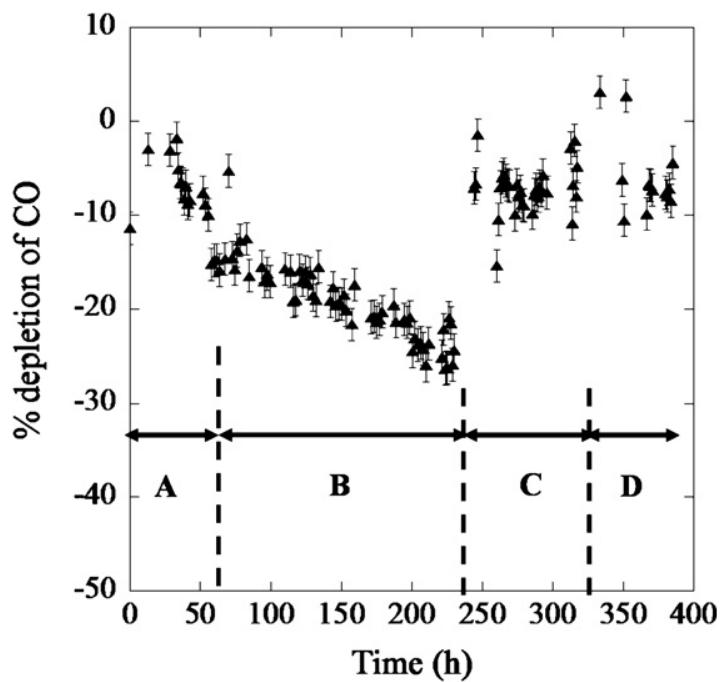

Figure 8. Plot of percentage depletion of $\mathrm{CO}$ versus time at different gas flow rates for a gas mixture consisting of $70 \mathrm{ppm} \mathrm{CO}$ and $0.7 \mathrm{ppm} \mathrm{CO}$ and an empty tube. Flow rate of gas in the tube in time steps $\mathrm{A}$ and $\mathrm{C}$ was maintained at $106 \mathrm{ml} \mathrm{min}^{-1}$, whereas the flow rate in the time steps $\mathrm{B}$ and $\mathrm{D}$ was maintained at $24 \mathrm{ml} \mathrm{min}^{-1}$ and $52 \mathrm{ml} \mathrm{min}^{-1}$, respectively.

becomes starved and the oxidation behavior shown by the metal will not be the representative of the performance in the plant. A sufficiently high flow rate of gases must be used to avoid a significant depletion of the reacting species in the gas mixture.

An experiment was conducted to determine the minimum flow rate of the gas mixture required to avoid the significant depletion of the reactants $\mathrm{CO}$ and $\mathrm{CO}_{2}$, which could cause starvation of the reactant during an experiment. The onset of starvation of reactive species inside the reaction zone was determined by the variation in the degree of depletion (difference in the inlet and outlet concentration) of the reacting species with the flow rate of the gas mixture. The flow rate at which the reactive species at the outlet is depleted by more than $10 \%$ from the inlet level was considered to be the onset of starvation and represents the minimum flow rate of the gas mixture that should be maintained in the experiment $[7,8]$.

A helium gas chemistry of $\mathrm{He}+70 \mathrm{ppm} \mathrm{CO}+0.7 \mathrm{ppm}$ $\mathrm{CO}_{2}$ was chosen to determine the starvation limit. A total of seven alloy 617 corrosion coupons, each with dimension $6.25 \mathrm{~mm} \times 6.25 \mathrm{~mm} \times 1.5 \mathrm{~mm}$, were exposed at $950{ }^{\circ} \mathrm{C}$ with the gas flow rate varying between $24 \mathrm{ml} \mathrm{min}^{-1}$ and $106 \mathrm{ml} \mathrm{min}^{-1}$. The surfaces of the samples were prepared by grit $800 \mathrm{SiC}$ paper. Prior to the experiment, the quartz tubes were baked for $30 \mathrm{~h}$ at $1000{ }^{\circ} \mathrm{C}$ under nitrogen gas at a flow rate of $90 \mathrm{ml} \mathrm{min}^{-1}$.

Figure 8 is a plot of the percentage depletion of $\mathrm{CO}$ at the outlet as a function of the exposure duration at different gas flow rates during the experiment. The flow rate of the gas mixture over the specimens was changed in four successive time steps 'A', 'B', 'C' and 'D' in figure 8. Proper care was taken to ensure that the concentrations of $\mathrm{CO}$ and $\mathrm{CO}_{2}$ at the inlet remained constant, while changing the flow rate in the tube. In time step A, which lasted for the first $56 \mathrm{~h}$, the gas 
flow rate of $106 \mathrm{ml} \mathrm{min}^{-1}$ was maintained over the corrosion coupons, and then in time step B the flow rate was decreased to $24 \mathrm{ml} \mathrm{min}-1$ for $\sim 170 \mathrm{~h}$. In time step $\mathrm{C}$, the flow rate was brought back to an initial flow rate of $106 \mathrm{ml} \mathrm{min}^{-1}$ to replicate the behavior seen in time step A, and finally, in time

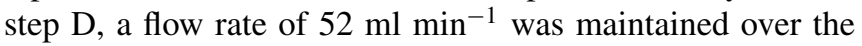
corrosion coupons and the inlet and outlet $\mathrm{CO}$ concentrations were recorded.

As shown in figure 8, during time steps $\mathrm{A}, \mathrm{C}$ and $\mathrm{D}$, where the flow rate of the gas mixture was either $106 \mathrm{ml} \mathrm{min}^{-1}$ or $52 \mathrm{ml} \mathrm{min}^{-1}$, the difference in the inlet and outlet concentration of $\mathrm{CO}$ was less than $10 \%$. However, in time step B with a gas flow rate of $24 \mathrm{ml} \mathrm{min}^{-1}$ the inlet and outlet concentration levels differed by more than $10 \%$. Based on the criterion that the environment should not be depleted in $\mathrm{CO}$ by more than $10 \%$, the flow rate in region $\mathrm{D}\left(52 \mathrm{ml} \mathrm{min}^{-1}\right.$, corresponding to the flow rate of $6.3 \mathrm{ml} \mathrm{cm}^{-2}$ surface area of the sample) was determined to be the minimum flow rate to avoid starvation.

\section{Validation of the facility}

The utility of the system is its capability to determine increases or decreases in the reacting gases between inlet and outlet, and to integrate those values over time to obtain a quantitative measure of the reaction products forming on the exposure coupons. This capability was validated by comparing the amount of the reaction gas produced or consumed with the weight change and microstructural characterization of the samples during the exposure of alloy 617 coupons to helium $+15 \mathrm{ppm}$ of $\mathrm{CO}$ and $1.5 \mathrm{ppm}$ of $\mathrm{CO}_{2}$ at $900{ }^{\circ} \mathrm{C}$ and $1000{ }^{\circ} \mathrm{C}$.

\subsection{System reliability for experiments in $\mathrm{He}-\mathrm{CO}-\mathrm{CO}_{2}$ gas at $900^{\circ} \mathrm{C}$ and $1000^{\circ} \mathrm{C}$}

The capability and reliability of the integrated system was verified by comparing the weight of the gases consumed or produced with the measured weight gain in the samples and the post-test microstructural characterization. To accomplish this verification, a total of five corrosion coupons of alloy 617 , each of dimension $6.25 \mathrm{~mm} \times 6.25 \mathrm{~mm} \times 1.5 \mathrm{~mm}$, were first oxidized for $100 \mathrm{~h}$ at $900{ }^{\circ} \mathrm{C}$ and then in the subsequent step were decarburized at $1000{ }^{\circ} \mathrm{C}$ for additional $100 \mathrm{~h}$. The gas chemistry and flow rate used in this test was $\mathrm{He}$ +15 ppm of $\mathrm{CO}+1.6 \mathrm{ppm}$ of $\mathrm{CO}_{2}$ and $5.8 \mathrm{l} \mathrm{h}^{-1}$, respectively. Before the experiment was started, the system was conditioned in the following manner: the tube was baked at $1025{ }^{\circ} \mathrm{C}$ for $24 \mathrm{~h}$ under the nitrogen gas flowing at a rate of $90 \mathrm{ml}$ $\min ^{-1}$, and then ultra-pure helium of $99.9999 \%$ purity was flowed to flush out the nitrogen and oxygen from the sealed tube. After the oxygen level dropped below the detection limit of $\sim 1 \mathrm{ppm}$, the furnace was brought down to $900{ }^{\circ} \mathrm{C}$, and the $\mathrm{CO}$ and $\mathrm{CO}_{2}$ concentration levels of $15 \mathrm{ppm}$ and 1.6 ppm, respectively, were established. The corrosion coupons, which were initially placed in the cold zone of the tube, were inserted inside the hot zone using the custom push rod shown in figure 3.

After $100 \mathrm{~h}$ of exposure at $900{ }^{\circ} \mathrm{C}$, all the samples were pushed out of the furnace and into the cold zone. The furnace

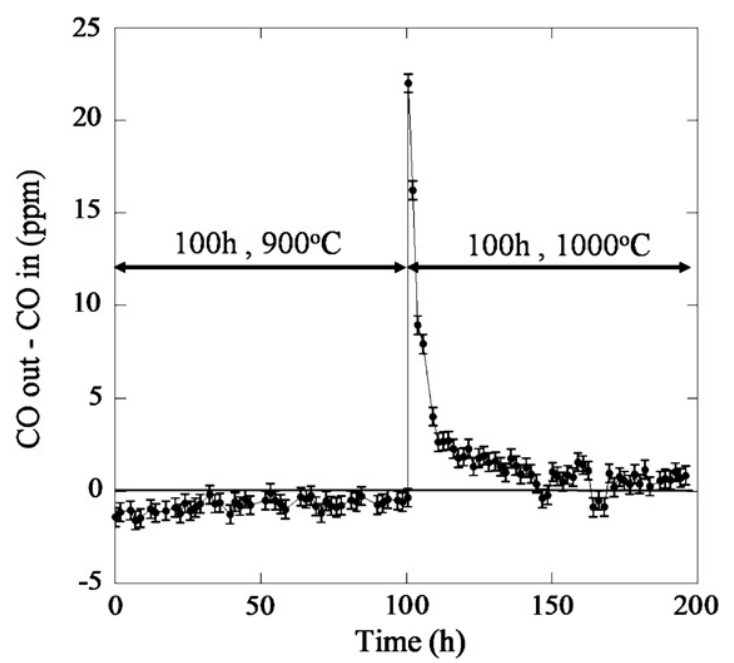

Figure 9. Plot of the difference of $\mathrm{CO}$ concentration at the outlet and inlet of the tube as a function of exposure duration. For the first $100 \mathrm{~h}$ the samples were exposed at $900^{\circ} \mathrm{C}$ and for the next $100 \mathrm{~h}$ the samples were exposed at $1000^{\circ} \mathrm{C}$.

temperature was then raised to $1000{ }^{\circ} \mathrm{C}$ and four out of the five oxidized samples were returned to the hot zone of the furnace for further exposure at $1000{ }^{\circ} \mathrm{C}$ for an additional 6,16 , 45 and $100 \mathrm{~h}$, respectively. At the completion of the exposure at $1000{ }^{\circ} \mathrm{C}$, the samples were removed from the hot zone and were cooled under flowing helium, followed by retrieval and weighing on a microbalance with a resolution of $0.01 \mathrm{mg}$.

4.1.1. Weight change after exposure at $900^{\circ} \mathrm{C}$ and $1000^{\circ} \mathrm{C}$. In order to determine the reliability of the gas analysis through the DIDGC, the measured weight gains in the samples during the experiment were compared with the weight of the gases consumed or produced. The increase in the weight of the sample was measured by a microbalance with a resolution of $0.01 \mathrm{mg}$, and the weight of the gases consumed or produced was calculated from the analysis of gases through the DIDGC. Figures 9 and 10 present the difference in the concentration levels of $\mathrm{CO}$ and $\mathrm{CO}_{2}$ at the outlet and inlet of the exposure section at $900{ }^{\circ} \mathrm{C}$ and $1000{ }^{\circ} \mathrm{C}$, respectively. A negative value in figures 9 and 10 denotes a net consumption of $\mathrm{CO}$ or $\mathrm{CO}_{2}$ causing the concentration level at the outlet to be lower than that at the inlet, whereas a positive value denotes a net production of $\mathrm{CO}$ or $\mathrm{CO}_{2}$ inside the reaction zone.

For the entire $100 \mathrm{~h}$ exposure duration at $900{ }^{\circ} \mathrm{C}$, a net consumption of $\mathrm{CO}$ and $\mathrm{CO}_{2}$ occurred by their reaction with the alloy. With the assumption that $\mathrm{Cr}$ is the primary reactive element in alloy 617 which forms oxides and carbides, the reaction of $\mathrm{CO}$ and $\mathrm{CO}_{2}$ with the sample increases the weight of the sample as per the following reactions:

$$
\begin{gathered}
2 \mathrm{Cr}+3 \mathrm{CO}_{2} \rightarrow \mathrm{Cr}_{2} \mathrm{O}_{3}+3 \mathrm{CO}, \\
27 \mathrm{Cr}+6 \mathrm{CO} \rightarrow 2 \mathrm{Cr}_{2} \mathrm{O}_{3}+\mathrm{Cr}_{23} \mathrm{C}_{6} .
\end{gathered}
$$

Reaction of $\mathrm{CO}_{2}$ increases the weight of the sample via incorporation of oxygen in the sample in the form of $\mathrm{Cr}_{2} \mathrm{O}_{3}$ (equation (1)), whereas the reaction of $\mathrm{CO}$ increases the weight 
Table 5. Balance sheet between the weight gain measured by microbalance and that calculated by the gas-phase analysis using equations (3) and (4).

\begin{tabular}{|c|c|c|c|c|}
\hline $\begin{array}{l}\text { Temperature, } \\
\text { time }\end{array}$ & $\begin{array}{l}\text { Net weight of the } \\
\text { sample measured by } \\
\text { microbalance } \\
\left(\mathrm{mg} \mathrm{mm}^{-2}\right) \times 10^{-3}\end{array}$ & $\begin{array}{l}\text { Wt gain calculated from } \mathrm{CO} \\
\text { consumption measured by the } \\
\text { DIDGC as per equation }(3) \\
\left(\Delta W_{\mathrm{CO}}\right)\left(\mathrm{mg} \mathrm{mm}^{-2}\right) \times 10^{-3}\end{array}$ & $\begin{array}{l}\text { Wt gain calculated from } \mathrm{CO}_{2} \\
\text { consumption measured by the } \\
\text { DIDGC as per equation }(4) \\
\left(\Delta W_{\mathrm{CO}_{2}}\right)\left(\mathrm{mg} \mathrm{mm}^{-2}\right) \times 10^{-3}\end{array}$ & $\begin{array}{l}\text { Net weight of the sample } \\
\text { calculated from the gas-phase } \\
\text { analysis }\left(\mathrm{mg} \mathrm{mm} \mathrm{mm}^{-2}\right) \times 10^{-3} \text {. } \\
\text { Net weight }=\text { initial wt }+ \\
\Delta W_{\mathrm{CO}}+\Delta W_{\mathrm{CO}_{2}}\end{array}$ \\
\hline $900^{\circ} \mathrm{C}, 100 \mathrm{~h}$ & $1.6 \pm 0.2$ & 1.2 & 0.1 & $1.2+0.1=1.3$ \\
\hline $1000^{\circ} \mathrm{C}, 100 \mathrm{~h}$ & $0.4 \pm 0.2$ & -2.6 & 1.1 & $1.6-2.6+1.1=0.1$ \\
\hline
\end{tabular}

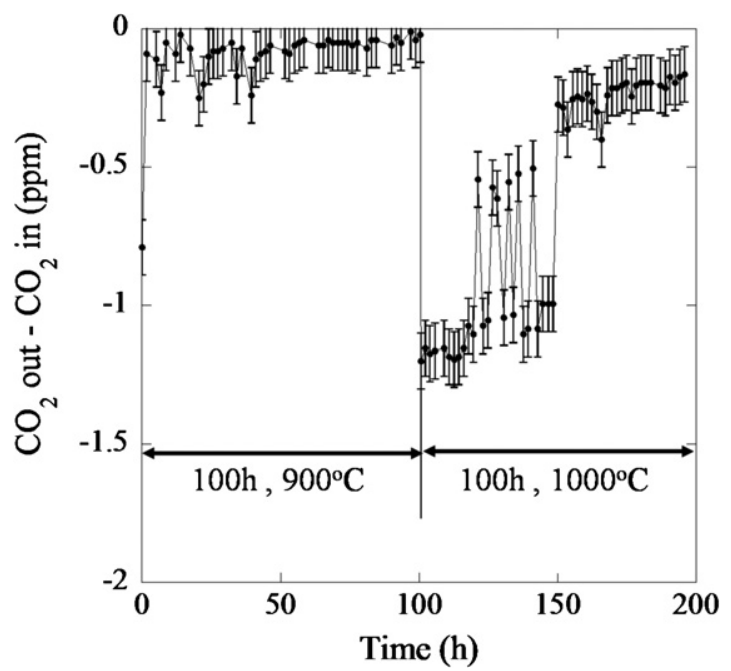

Figure 10. Plot of the difference of $\mathrm{CO}_{2}$ concentration at the outlet and inlet of the tube as a function of exposure duration. For the first $100 \mathrm{~h}$ the samples were exposed at $900{ }^{\circ} \mathrm{C}$ and for the next $100 \mathrm{~h}$ the samples were exposed at $1000^{\circ} \mathrm{C}$.

of the sample via incorporation of both carbon and oxygen in the sample in the form of $\mathrm{Cr}_{2} \mathrm{O}_{3}$ and internal carbides, which are assumed to be primarily $\mathrm{Cr}_{23} \mathrm{C}_{6}$ (equation (2)). Figure 11 shows the low- and high-magnification microstructures of the sample exposed for $100 \mathrm{~h}$ at $900{ }^{\circ} \mathrm{C}$. As is evident from the low-magnification image, the inward diffusion of carbon resulted in the precipitation of internal carbides along the grain boundaries and the twin boundaries. The white carbides seen in the microstructure are $\mathrm{M}_{6} \mathrm{C}$ carbides, whereas the black carbides are $\mathrm{M}_{23} \mathrm{C}_{6}$ type of carbides (where $\mathrm{M}=\mathrm{Cr}$, Mo). Further, the high-magnification image in figure 11 shows that the oxygen was mainly present in the sample in the form of an external $\mathrm{Cr}_{2} \mathrm{O}_{3}$ film.

The importance of tracking the changes in reactant and product gases is that it will provide information on the reactions occurring in the sample. So the change in reactants and products should match those measured on the sample itself by changes in its weight. The increase in weight of the sample due to reaction with $\mathrm{CO}$ (equation (1)) and $\mathrm{CO}_{2}$ (equation (2)) was calculated from the area under the $\mathrm{CO}$ and $\mathrm{CO}_{2}$ curves in figures 9 and 10 using

the weight gain due to $\mathrm{CO}$ consumption $\left(\Delta W_{\mathrm{CO}}\right)$

$$
=\frac{I_{\mathrm{CO}} \times \dot{V} \times M_{\mathrm{CO}}}{V_{\mathrm{m}} \times A},
$$

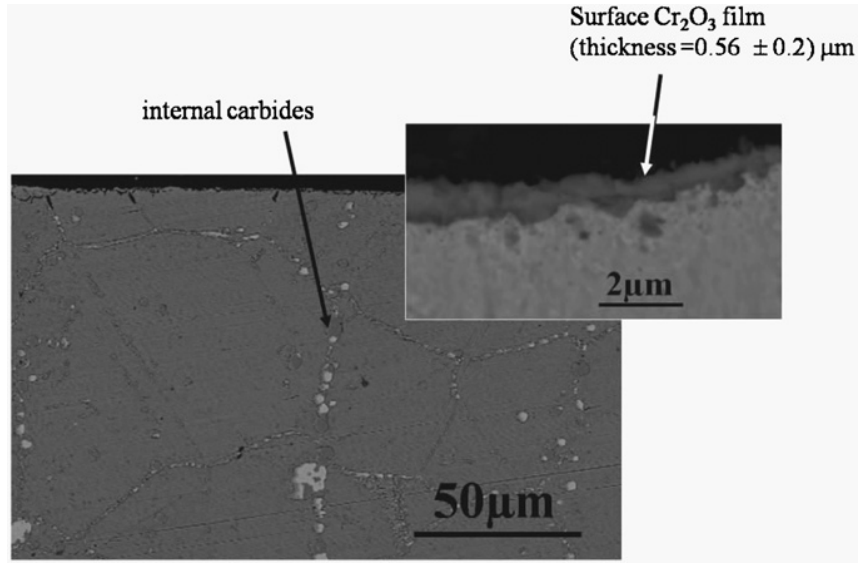

Figure 11. Low- and high-magnification back scattered electron (BSE) image of the sample oxidized at $900{ }^{\circ} \mathrm{C}$ for $100 \mathrm{~h}$ in $\mathrm{He}+$ $15 \mathrm{ppm} \mathrm{CO}+1.6 \mathrm{ppm} \mathrm{CO}_{2}$ gas mixture. Low-magnification image shows the formation of internal carbides along the grain boundaries. The white carbides are $\mathrm{M}_{6} \mathrm{C}$ type of carbides, and black carbides are $\mathrm{M}_{23} \mathrm{C}_{6}$ (where $\mathrm{M}$ is $\mathrm{Cr}$, Mo) type of carbides. The

high-magnification image shows the microstructure of the sample near the surface. An external film of $\mathrm{Cr}_{2} \mathrm{O}_{3}$ of thickness $0.56 \mu \mathrm{m}$ formed due to exposure.

the weight gain due to $\mathrm{CO}_{2}$ consumption $\left(\Delta W_{\mathrm{CO}_{2}}\right)$

$$
=\frac{I_{\mathrm{CO}_{2}} \times \dot{V} \times M_{\mathrm{O}_{2}}}{2 \times V_{\mathrm{m}} \times A},
$$

where $I_{\mathrm{CO}}$ and $I_{\mathrm{CO}_{2}}$ correspond to the area between the $x$-axis and the $\mathrm{CO}$ (figure 9) and $\mathrm{CO}_{2}$ (figure 10) curve (in mole-h), $\dot{V}$ is the flow rate of the gas mixture (in $1 \mathrm{~h}^{-1}$ ), $M_{\mathrm{CO}}$ and $M_{\mathrm{O}_{2}}$ are the molar weights of $\mathrm{CO}$ and $\mathrm{O}_{2}$, respectively, $V_{\mathrm{m}}$ is the molar volume of the gas mixture (in $\left.1 \mathrm{~mol}^{-1}\right)\left(V_{\mathrm{m}}=\frac{R \times T}{P}, R\right.$ is the universal gas constant, $T$ is $298 \mathrm{~K}$ and $P$ is $1 \mathrm{~atm})$ and $A$ is the surface area of the sample (in $\mathrm{mm}^{2}$ ). The factor $\frac{1}{2}$ in equation (4) indicates that only half of the oxygen contained in $\mathrm{CO}_{2}$ is incorporated in the sample in the form of $\mathrm{Cr}_{2} \mathrm{O}_{3}$ (see equation (1)).

A balance sheet describing the measured weight gain and the calculated weight gain due to the $\mathrm{CO}$ and $\mathrm{CO}_{2}$ reaction is shown in columns 2 and 4 of table 5 , respectively. The net weight gain measured by the microbalance after the $100 \mathrm{~h}$ exposure at $900{ }^{\circ} \mathrm{C}$ was $1.6 \pm 0.3 \times 10^{-3} \mathrm{mg} \mathrm{mm}^{-2}$, which is in reasonably good agreement with the calculated weight gain of $1.3 \times 10^{-3} \mathrm{mg} \mathrm{mm}{ }^{-2}$ from the gas phase analysis. This analysis shows that in impure helium the $\mathrm{CO}$ acts as 
an oxidizing and carburizing gas, whereas $\mathrm{CO}_{2}$ acts as an oxidizing gas.

A similar mass balance for the $100 \mathrm{~h}$ exposure at $1000{ }^{\circ} \mathrm{C}$ was also performed. As shown in figure 9, in contrast to oxidation at $900{ }^{\circ} \mathrm{C}$ where $\mathrm{CO}$ reacted with the sample, exposure at $1000^{\circ} \mathrm{C}$ resulted into a net production of $\mathrm{CO}$ inside the reaction zone. The production of $\mathrm{CO}$ at $1000{ }^{\circ} \mathrm{C}$ has been associated with decarburization of the sample $[9,10]$, whereas the reaction of $\mathrm{CO}_{2}$ results into oxidation of the sample as per equation (2). The production of $\mathrm{CO}$ will result in a weight loss in the sample, whereas the reaction of $\mathrm{CO}_{2}$ results in a weight gain in the sample (figure 10). Thus, the total weight of the sample measured by the microbalance is the sum of the weight loss due to $\mathrm{CO}$ production and the weight gain due to the reaction with $\mathrm{CO}_{2}$. Table 5 shows the balance sheet for the weight change associated with the $\mathrm{CO}$ and $\mathrm{CO}_{2}$ reaction and the weight change measured by the microbalance in the sample exposed at $1000{ }^{\circ} \mathrm{C}$ for $100 \mathrm{~h}$. The weight loss in the sample due to $\mathrm{CO}$ production was $-2.6 \times 10^{-3} \mathrm{mg} \mathrm{mm}^{-2}$ (calculated using equation (3)) and the weight gain in the sample due to $\mathrm{CO}_{2}$ reaction was $1.1 \times 10^{-3} \mathrm{mg} \mathrm{mm}^{-2}$ (calculated using equation (4)), which amounts to a net weight loss of $-1.5 \times$ $10^{-3} \mathrm{mg} \mathrm{mm}^{-2}$ in the sample. Adding this weight loss to the total weight of the sample prior to the exposure at $1000{ }^{\circ} \mathrm{C}$ $\left(1.6 \times 10^{-3} \mathrm{mg} \mathrm{mm}^{-2}\right)$ gives a sample weight of $0.1 \times 10^{-3}$ $\mathrm{mg} \mathrm{mm} \mathrm{m}^{-2}$, which is comparable to the measured weight of the sample of $0.4 \pm 0.2 \times 10^{-3} \mathrm{mg} \mathrm{mm}^{-2}$.

Thus, the good agreement between the weight of the samples calculated through gas-phase analysis and the weight change measured by the microbalance confirms the reliability of the system to quantitatively account for the masses of reactants and products involved in the oxidation reaction.

4.1.2. Metallographic analysis of the sample exposed at $900{ }^{\circ} \mathrm{C}$ for $100 \mathrm{~h}$. To gain greater confidence in the reliability of the facility to quantitatively account for masses of reactants and products during the high-temperature exposure experiment, the weight of the gases reacted/produced was compared with the weight of the oxygen and carbon content in the alloy from the microstructural analysis.

The weight of oxygen in the alloy can be calculated from the total weight gain in the sample using the identity that 1 mole of CO has an oxygen weight fraction of $0.57(16 / 28)$ and as per equation (2), it should be present in the sample in the form of $\mathrm{Cr}_{2} \mathrm{O}_{3}$. Further, 1 mole of $\mathrm{CO}_{2}$ has an oxygen weight fraction of $0.72(32 / 44)$, out of which only half, i.e. 0.36 , is associated with $\mathrm{Cr}_{2} \mathrm{O}_{3}$ (equation (1)) and the other half is associated with $\mathrm{CO}$. The total weight of oxygen in the sample after $100 \mathrm{~h}$ of exposure at $900{ }^{\circ} \mathrm{C}$ was calculated to be $0.8 \times 10^{-3} \mathrm{mg} \mathrm{mm}^{-2}$ by the gas phase analysis. The weight of oxygen in the sample was also calculated by measuring the thickness of the $\mathrm{Cr}_{2} \mathrm{O}_{3}$ film formed (figure 11) according to the following equation:

weight of oxygen contained in the $\mathrm{Cr}_{2} \mathrm{O}_{3}$ film

$$
=\rho_{\mathrm{Cr}_{2} \mathrm{O}_{3}} \times t_{\mathrm{Cr}_{2} \mathrm{O}_{3}} \times \frac{3 M_{\mathrm{O}}}{M_{\mathrm{Cr}_{2} \mathrm{O}_{3}}},
$$

where $\rho_{\mathrm{Cr}_{2} \mathrm{O}_{3}}$ is the density of $\mathrm{Cr}_{2} \mathrm{O}_{3}\left(5.21 \mathrm{mg} \mathrm{mm}^{-3}\right), t_{\mathrm{Cr}_{2} \mathrm{O}_{3}}$ is the thickness of the $\mathrm{Cr}_{2} \mathrm{O}_{3}$ film (in mm), $M_{\mathrm{O}}$ is the atomic
Table 6. Balance sheet describing the weight of oxygen in the sample calculated by the gas-phase analysis and microstructural analysis using equation (5).

\begin{tabular}{lll}
\hline $\begin{array}{l}\text { Temperature, } \\
\text { time }\end{array}$ & $\begin{array}{l}\text { Wt of oxygen in the } \\
\text { sample } \\
\left(\mathrm{mg} \mathrm{mm}^{-2}\right) \times 10^{-3}\end{array}$ & $\begin{array}{l}\text { Wt of oxygen contained in the } \\
\mathrm{Cr}_{2} \mathrm{O}_{3} \text { film as per equation (5) } \\
\left(\mathrm{mg} \mathrm{mm}^{-2}\right) \times 10^{-3}\end{array}$ \\
\hline $\begin{array}{l}900{ }^{\circ} \mathrm{C}, \\
100 \mathrm{~h}\end{array}$ & 0.8 & $0.9 \pm 0.3$ \\
\hline
\end{tabular}

weight of oxygen and $M_{\mathrm{Cr}_{2} \mathrm{O}_{3}}$ is the molar weight of $\mathrm{Cr}_{2} \mathrm{O}_{3}$ (in

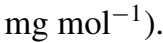

The weight of oxygen associated with the $\mathrm{Cr}_{2} \mathrm{O}_{3}$ film was estimated to be $0.9 \pm 0.3 \times 10^{-3} \mathrm{mg} \mathrm{mm}^{-2}$, which is in a good agreement with the $0.8 \times 10^{-3} \mathrm{mg} \mathrm{mm}^{-2}$ of oxygen from reaction with $\mathrm{CO}$ and $\mathrm{CO}_{2}$ (table 6 ). Thus, the microstructural analysis also substantiates that the facility can reliably quantify the masses of reactants and products during oxidation.

\section{Summary}

A controlled environment facility was constructed for determining the high-temperature corrosion of alloys in helium gas containing part per million levels of $\mathrm{CO}, \mathrm{CO}_{2}, \mathrm{H}_{2}$ and $\mathrm{CH}_{4}$ as impurities. The key features of the facility are as follows:

(i) capability of exposing multiple specimens in up to seven different controlled impurity environments simultaneously (the exposure of multiple specimens facilitates the determination of the oxidation kinetics as a function of helium gas chemistry);

(ii) control of experimental variables such as inlet gas chemistry $( \pm 3.5 \%$ of the target value $)$, flow rate $( \pm 10 \mathrm{ml}$ $\left.\min ^{-1}\right)$ and temperature $\left(1200 \pm 2{ }^{\circ} \mathrm{C}\right)$ for long exposure durations $(>1000 \mathrm{~h})$, which ensures the reliability of the experiment; and

(iii) reliable gas analysis for quantifying the concentrations of impurities in the range of $1 \mathrm{ppm}$ level in both the inlet and outlet gas streams.

A comparison between the weight gain in a nickel-base alloy 617 sample exposed at $900{ }^{\circ} \mathrm{C}$ and $1000{ }^{\circ} \mathrm{C}$ measured by microbalance, and by the difference in the inlet and outlet concentrations of the reactants and the products via gasphase analysis demonstrates the utility and reliability of the integrated facility.

\section{Acknowledgments}

Financial support for this project by the United States Department of Energy is greatly acknowledged (under contract number DE-FC07-05ID14660).

\section{References}

[1] Klower J and Heubner U 1985 Carburization of nickel-based alloys and its effect on the mechanical properties Mater. Corros. 49 237-45

[2] Shankar P S and Natesan K 2007 Effect of trace impurities in helium on the creep behavior of alloy 617 for very high temperature reactor applications J. Nucl. Mater. 366 28-36 
[3] Rouillard F, Cabet C, Wolski K and Pijolat M 2007 Oxide layer formation and stability on a Nickel-base alloy in impure helium at high temperature Oxid. Met. 68 133-48

[4] Cabet C, Monnier A and Terlain A 2004 Corrosion of high temperature alloys in the coolant helium of a gas cooled reactor Mater. Sci. Forum 461-464 1165-72

[5] Wright R N 2005 Controlled impurity helium high temperature helium materials test loop INL Draft No. INL/EXT-05-00653, Idaho Falls, USA, August

[6] Christ H J, Schwanke D, Uihlein Th and Sockel H G 1988 Mechanism of high temperature corrosion in helium containing small amounts of impurities-I. Theoretical and experimental characterization of the gas phase Oxid. Met. $301-26$
[7] Wilson D F 2005 Potential helium test environment for the next generation nuclear plant materials $O R N L$ Draft no. ORNL/TM-2005/92, Oak Ridge, USA

[8] Kimball O F and Plumlee D E 1985 Gas/metal interaction studies in simulated HTGR helium Report no. 131, contract no DE-AC03-80ET34034, Schenectady, NY, USA

[9] Quadakkers W J 1985 Corrosion of high temperature alloys in the primary circuit helium of high temperature gas cooled reactors. Part II-experimental results Werkst. Korros. 36 335-47

[10] Kumar D and Was G S 2009 Mechanism of decarburization of alloy 617 at $1000^{\circ} \mathrm{C}$ in helium containing $\mathrm{CO}$ and $\mathrm{CO}_{2}$ as impurities Proc. Materials Research Society (Boston, USA, 5-8 December) vol 1125 paper no. 1125-R06-02 